\title{
An in vitro evaluation of the zirconia surface treatment by mesoporous zirconia coating on its bonding to resin cement
}

\author{
Yanli Zhang ${ }^{\mathrm{a}}$, Ting Sun ${ }^{\mathrm{b}}$, Ruoyu Liu ${ }^{\mathrm{a}}$, Xiaoli Feng ${ }^{\mathrm{a}}$, Aijie Chen ${ }^{\mathrm{a}}$ and Longquan Shao ${ }^{\mathrm{a},{ }^{*}}$ \\ ${ }^{a}$ Department of Stomatology, Nanfang Hospital, Southern Medical University, Guangzhou 510515, \\ China \\ ${ }^{b}$ The Medical Centre of Stomatology, The 1st Affiliated Hospital of Jinan University, Guangzhou \\ 510630, China
}

\begin{abstract}
The effect of zirconia surface treatment by mesoporous zirconia coating on the microtensile bond strength (MTBS) between zirconia and resin cement was investigated in this work. 160 zirconia specimens were prepared and divided into four groups according to surface treatments: (1) airborne-particle-abrasion treatment (APA); (2) glass infiltration and hydrofluoric acid treatment (GI+HF); (3) mesoporous zirconia coating (MZ); and (4) no treatment (C). The as-prepared zirconia specimens were bonded using Panavia F2.0 and RelyX Unicem. The MTBS values were tested using a universal testing machine, and data were analyzed using ANOVA and SNK methods $(\alpha=0.05)$. The MTBS values obtained after GI+HF and $\mathrm{MZ}$ treatments were significantly higher than those obtained after APA and C treatments $(\mathrm{P}<0.05)$, especially for samples cemented with Panavia F2.0. The results reveal that zirconia surface treatments using GI+HF and MZ yield higher bond strength than those using APA or C, regardless of the resin cements.
\end{abstract}

Keywords: Mesoporous zirconia coating, microtensile bond strength, surface treatment, resin cement

\section{Introduction}

The superior mechanical properties, advanced aesthetics, and metal-free substructure of zirconia make it an excellent candidate for dentistry applications [1]. Dental zirconia is often yttria-stabilized tetragonal zirconia poly-crystals (Y-TZP) or yttria partially stabilized zirconia (YSZ). As a result of the transformation toughening mechanism, Y-TZP has been shown to have a greater flexural strength (900 to $1200 \mathrm{MPa}$ ) and fracture toughness $\left(9\right.$ to $10 \mathrm{MPa} / \mathrm{m}^{2}$ ) compared to traditional ceramics [2]. The long-term application of zirconia-based restorations in all positions of the dental arch has been reported to be optimistic [3]. However, chipping of the veneering ceramics and loss of retention have been reported as the most common reasons for failures of zirconia-based restorations [4]. Retention failures have been attributed to improper tooth preparation, incorrect luting technique, or improper cement selection [5]. Zirconia-based restorations exhibit high fracture resistance and can be cemented

\footnotetext{
${ }^{*}$ Corresponding author: Longquan Shao, Department of Stomatology, Nanfang Hospital, Southern Medical University, Guangzhou 510515, China. Tel.: 15989283921; Fax: 62787153; E-mail: shaolongquan@smu.edu.cn.
}

0959-2989/14/\$27.50 @ 2014 - IOS Press and the authors. 
with conventional luting cements according to the manufacturer's recommendations. However, resin cements have been recommended for better retention and prevention of secondary caries between a substrate tooth and a restoration [6,7]. Adhesion to the zirconia ceramic is expected for most luting cements given their content of functional polymers or monomers [8]. Various surface energies of functional polymers or monomers, can lead to different interfacial chemical interactions and bonding potentials with the zirconia ceramic.

Additionally, the bond strength of zirconia surface treatments can be augmented by the addition or subtraction of surface coating materials. APA is a common way to roughen and clean the bonding surfaces of zirconia and resin, enhancing the micromechanical interlocking performance of resin; although its role in bonding zirconia to resin cement has not yet been confirmed [9]. Another method to improve bonding strength is the application of hydrofluoric acid. However, on its own, it is not capable of promoting sufficient macroscopic interaction, as the material is acid resistant. Cantoroa et al. [10] proposed using selective infiltration etching technology where they achieved higher bond strengths compared with other techniques, such as APA treatment. Nevertheless, several factors may affect the outcome, such as the components of the glass, the sintering process, and the concentration of HF solution. For these reasons, self-regulating glass infiltration, integrated with pre-sintered zirconia blocks that are combined with $10 \%$ concentration of hydrofluoric acid treatment, have been adopted to improve the bond strength between zirconia and resin cement.

More recently, the field of biomedical research has shown a growing interest in nanostructured mesoporous zirconia materials, such as those composed of zirconium with nanometric pores. This material exhibits unique features of high biocompatibility with high surface area and pore volumes. Teng et al. [11] reported that when porous zirconia powder was sintered onto the zirconia blocks, sufficient core-veneer bond strength was achieved for the zirconia restorations. However, little information is available on the application of mesoporous zirconia coating as a surface conditioning method to improve the zirconia-resin bond. Therefore, the purpose of the present study was to investigate the effects of a simple, and novel, surface treatment method using a mesoporous zirconia coating on the MTBS.

\section{Materials and methods}

\subsection{Specimen preparation}

160 cylinder-shaped $(12.00 \mathrm{~mm}$ diameter $\times 5.25 \mathrm{~mm}$ height $)$ zirconia ceramic blocks (Cercon, DeguDent, Hanau, Germany) were fabricated according to the manufacturer's instructions. The specimens were polished using 1200-grit silicon carbide abrasive (St. Paul, USA) to ensure consistent surface roughness.

\subsection{Surface treatment}

The specimens were randomly assigned into one of four surface conditioning groups:

(1) Airborne-particle-abrasion (APA): APA was performed using $\mathrm{Al}_{2} \mathrm{O}_{3}$ particles with a grain size of $50 \mu \mathrm{m}$. The abrasion was executed with an air abrasion device (JNBP-3; Jianian utong Co Ltd; Tianjin, China) at a pressure of 2.8 bar and was applied, in circular motions, both parallel and perpendicular to the long axis of the cylinders. The working distance and time was $10 \mathrm{~mm}$ and $10 \mathrm{~s}$ respectively. 
(2) Glass infiltration and hydrofluoric acid (GI+HF): The composition of the silicate glass included $20 \mathrm{wt} \% \mathrm{La}_{2} \mathrm{O}_{3}, 20 \mathrm{wt} \% \mathrm{SiO}_{2}, 15 \mathrm{wt} \% \mathrm{~B}_{2} \mathrm{O}_{3}, 15 \mathrm{wt} \% \mathrm{BaO}, 10 \mathrm{wt} \% \mathrm{Al}_{2} \mathrm{O}_{3}, 5 \mathrm{wt} \% \mathrm{ZrO}_{2}, 5 \mathrm{wt} \% \mathrm{Y}_{2} \mathrm{O}_{3}, 4$ $\mathrm{wt} \% \mathrm{TiO}_{2}, 2 \mathrm{wt} \% \mathrm{CaO}, 1 \mathrm{wt} \% \mathrm{CeO}_{2}$, and $1 \mathrm{wt} \% \mathrm{Fe}_{2} \mathrm{O}_{3}$. The glass was applied to the top surfaces of the pre-sintered zirconia samples which were then thermally treated at $1350^{\circ} \mathrm{C}$ for $2 \mathrm{~h}$. Afterwards, the surface treated specimens were etched in hydrofluoric acid solution $(10 \% \mathrm{HF})$ for $30 \mathrm{~min}$.

(3) Mesoporous zirconia coating (MZ): The mesoporous zirconia was synthesized using a standardized procedure. An aqueous solution of $\mathrm{Zr}\left(\mathrm{SO}_{4}\right)_{2} \cdot 4 \mathrm{H}_{2} \mathrm{O}$ was used as the inorganic source, while an aqueous solution of $\mathrm{C}_{16} \mathrm{TMABr}$ was utilized as the surfactant with a mole ratio of $0.32: 1$. The solutions were stirred until they were completely dissolved followed by an ageing process. The sample was then hydro-thermally treated for $48 \mathrm{~h}$ at $110^{\circ} \mathrm{C}$. The resulting material was dissolved in $98 \%$ $\mathrm{H}_{3} \mathrm{PO}_{4}$ and coated onto the surfaces of the pre-sintered zirconia blocks; the treated cylinders were calcinated at $500^{\circ} \mathrm{C}$ for $6 \mathrm{~h}$. This procedure removed the template of $\mathrm{C}_{16} \mathrm{TMABr}$ and the mesoporous zirconia was sintered onto the specimen surfaces.

(4) No treatment (C): Resin cement was applied to the zirconia without any treatment.

\subsection{Fabrication of composite resin blocks}

Filtek Z250 Universal Restorative (3M ESPE, USA) was used as the composite resin. It was condensed into a plastic mold, and each layer was light polymerized with light-emitting diodes (Dentsply, USA) for $40 \mathrm{~s}$. Following polymerization, the discs were stored in water at $37^{\circ} \mathrm{C}$ for $24 \mathrm{~h}$ prior to bonding.

\subsection{Preparation of microtensile bond strength specimens}

Each ceramic block was bonded to a composite resin block under a load of $7 \mathrm{~N}$ for 10 min using Panavia F2.0 (Kuraray CO., Okayama, Japan) or RelyX Unicem (3M ESPE, USA) cements according to the manufacturer's instructions. A LED curing light was used to polymerize the luting agent for $40 \mathrm{~s}$ from each direction. The prepared specimens were sectioned vertically into $1 \mathrm{~mm}$-thick slabs using a low-speed diamond saw (Struers GmbH, Denmark). Each slab was serially sectioned into $1.0 \mathrm{~mm} \times 1.0$ $\mathrm{mm}$ sticks as required for the microtensile tests. The specimens were baseline tested immediately after the $24 \mathrm{~h}$ storage in water at $37^{\circ} \mathrm{C}$.

\subsection{Microtensile bond strength test}

A universal testing machine (Shimadzu, Japan) was used to apply microtensile loading and the resulting microtensile bond strengths $(\sigma)$ of the prepared specimen were calculated according to the following formula:

$$
\sigma=\mathrm{PA}^{-1}
$$

where $\mathrm{P}$ is the load $(\mathrm{N})$ at the moment of failure and $\mathrm{A}$ is the surface area of bonding $\left(\mathrm{mm}^{2}\right)$. 


\subsection{Observation of cement/ceramic bonded interface}

Three specimens from each group cemented with Panavia F2.0 were used for cement-ceramic interfacial analysis. Bonded specimens were polished and ultrasonicated in $96 \%$ ethanol for 15 min then dried. The zirconia-resin cement interface was assessed with SEM (TM3000/Hitachi, Japan).

\subsection{Statistical analysis}

The results of the MTBS test were analyzed with a 2-way ANOVA and SNK test $(\alpha=0.05)$ to determine if significant differences existed between surface conditioning methods, and resin cements. All data were analyzed with SPSS 13.0.

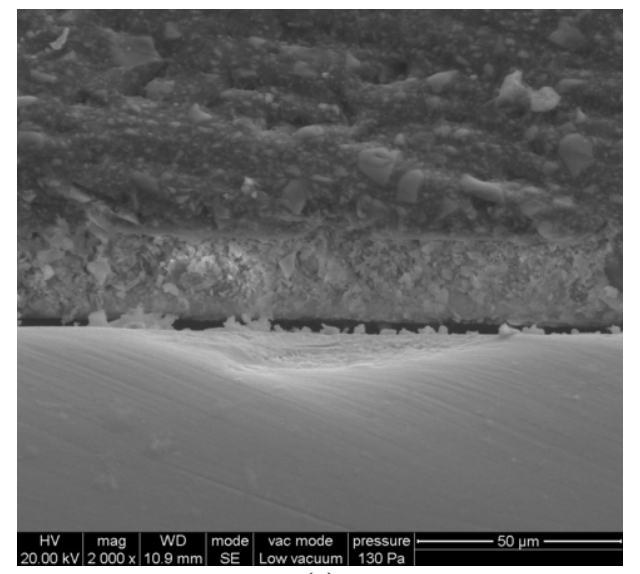

(a)

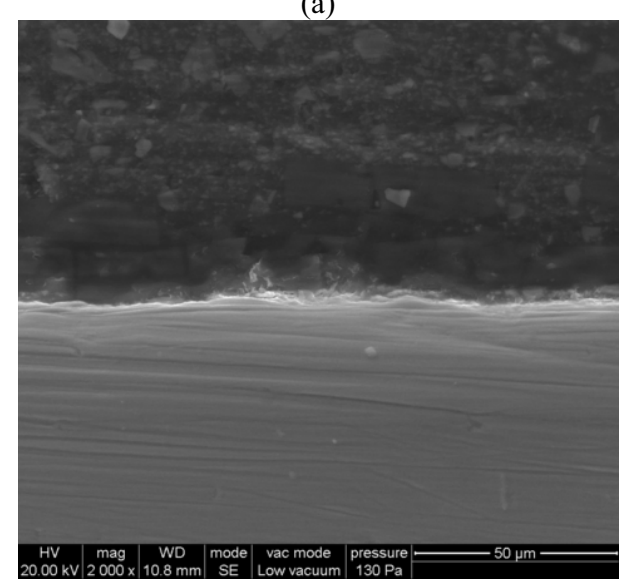

(c)

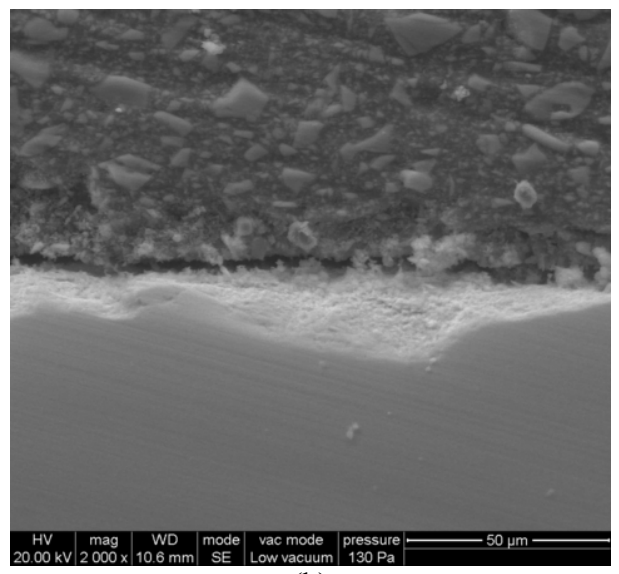

(b)

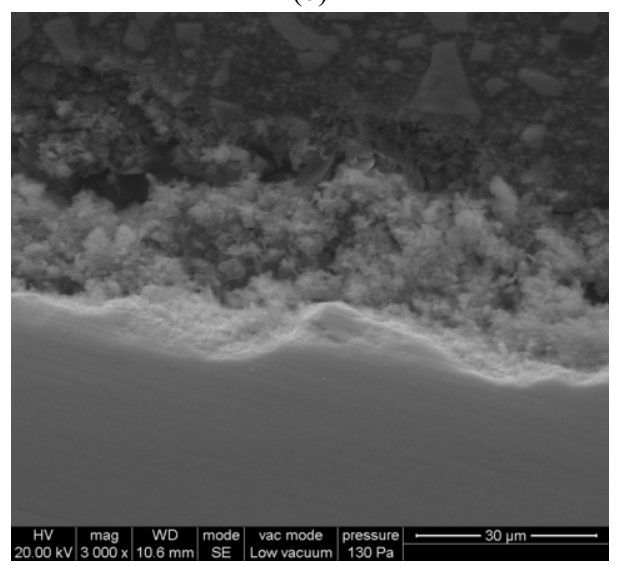

(d)

Fig. 1. The microstructural features of cross-section interfacial analysis (original magnification $\times 3000$ ): (a) Control group; (b) APA group; (c) GI+HF group; (d) MZ group, which demonstrates micromorphology of zirconia-cement bonded interface. 


\section{Results}

Table 1

Mean microtensile bond strength (Mpa) and standard deviation (SD)

\begin{tabular}{llll}
\hline Treatment & Resin cement & Mean $(\mathrm{Mpa})$ & SD \\
\hline APA & Rely X Unicem & $15.93^{\mathrm{al}}$ & 1.13 \\
GH & Rely X Unicem & $19.71^{\mathrm{b} 1}$ & 1.86 \\
MZ & Rely X Unicem & $19.02^{\mathrm{b} 1}$ & 1.40 \\
C & Rely X Unicem & $10.34^{\mathrm{c} 1}$ & 1.13 \\
APA & Panavia F2.0 & $17.38^{\mathrm{a} 2}$ & 1.50 \\
GH & Panavia F2.0 & $22.15^{\mathrm{b} 2}$ & 1.25 \\
MZ & Panavia F2.0 & $21.51^{\mathrm{b} 2}$ & 1.61 \\
C & Panavia F2.0 & $11.17^{\mathrm{c1}}$ & 0.95 \\
\hline
\end{tabular}

Means with different capital letter superscripts were statistically different at $P<0.05$.

\subsection{Microscopy}

The SEM images of a cross sectional view of the resin cement-ceramic structures is shown in Figure 1. Figure 1(a) shows the smooth interface without any treatment and Figure 1(b) shows that the sandblasted treatment resulted in a relatively irregular interface with the cements. The conditioning treatment with GI+HF, more closely resembled the combination between zirconia and resin cement show in Figure 1(c). The resin cement penetrated into the mesoporous zirconia substrate (Figure 1(d)).

\subsection{Microtensile bond strength}

The mean MTBS values and the standard deviations (SD) of the samples were $21.51 \pm 1.61 \mathrm{MPa}$ and 19.02 $\pm 1.40 \mathrm{MPa}$ for the MZ specimens in both groups of resin cements and $22.15 \pm 1.25 \mathrm{MPa}$ and $19.71 \pm 1.86 \mathrm{MPa}$ for the GI+HF specimens (Table 1). There were no statistical differences between the two groups $(P>0.05)$, while the values obtained after GI+HF and MZ treatments were significantly higher than those obtained after the APA and $\mathrm{C}$ treatments $(P<0.05)$. This was especially true for the specimens cemented with Panavia F2.0.

\section{Discussion}

\subsection{Surface treatment and microtensile bond strength}

In this study, the untreated zirconia ceramic exhibited the lowest MTBS compared to the other samples. This finding can be explained by the lower surface energy and wettability performance of the pristine zirconia, consistent with previous work $[12,13]$. Therefore, acid-resistant ceramics require special surface treatments to improve bonding with the resin cement.

The inertness of zirconia makes it difficult to obtain excellent bonding with resin cement and as a result, several approaches have been introduced to increase the surface roughness of ceramics to obtain satisfactory mechanical interlocking performance [14]. Blatz et al. [15] and Wolfart et al. [16] proposed that APA with $\mathrm{Al}_{2} \mathrm{O}_{3}$ is a preferred surface treatment method for high-strength ceramic materials such as alumina and zirconia. During the abrading process, the contaminated surface layer is removed and the roughened surface provides mechanical interlocking with the adhesive, a finding 
confirmed in the present study. The results here show that MTBS on zirconia treated with APA is significantly higher than that of the control group, regardless of the resin cement. However, APA may create sub-critical micro-cracks that could propagate and decrease the long-term performance of restoration by approximately $20 \%$ to $30 \%$ [17]. For this reason, a more effective and appropriate surface conditioning method is needed.

In the current investigation, a modification of the GI+HF procedure proposed in previous work was used [18]. The theory is based on the application of the glass infiltration agent onto the zirconia surface, which can be etched by $10 \%$ hydrofluoric acid, leaving the three-dimensional porous structure on the zirconia surface. The research showed that, when compared to APA, the GI+HF treatment is more effective in producing higher bond strengths between the composite resin and the high-strength ceramic substrate; this is consistent with the present work. However, the above investigations did not use the same glass percentages or infiltration temperatures. In the present study, a self-regulating glass with low viscosity was applied and sintered onto the zirconia blocks, allowing selective diffusion of the glass between the pre-stressed grain boundaries. Furthermore, the thermal expansion coefficient of the infiltrating agent should be lower than Y-TZP $\left(10.5 \times 10^{-6} \mathrm{~K}^{-1}\right.$, from 25 to $\left.450^{\circ} \mathrm{C}\right)$ to be chemically compatible with 3 Y-TZP to avoid adverse chemical degradation in a reactive environment. After the agent was dissolved with hydrofluoric acid, the surface of zirconia was transformed into a three-dimensional structure that can improve mechanical retention with the resin cement.

Despite the bond strength being significantly greater in the MZ group when compared to the APA and $\mathrm{C}$ groups, there was no significant difference between the GI+HF and MZ groups. Mesoporous zirconia was produced by mixing $\mathrm{Zr}\left(\mathrm{SO}_{4}\right)_{2} \cdot 4 \mathrm{H}_{2} \mathrm{O}$ with $\mathrm{C}_{16} \mathrm{TMABr}$ at a mole ratio of $0.32: 1$. During this procedure, the mesoporous zirconia was subjected to a thermal heat treatment at $500^{\circ} \mathrm{C}$ for $6 \mathrm{~h}$. After sintering, the template of $\mathrm{C}_{16} \mathrm{TMABr}$ was removed and the mesoporous zirconia was characterized as a porous structure exhibiting favorable compatibility with the zirconia blocks. The modified surface was different from the other surfaces in that it possessed a rough mesoporous structure. This provided interlocking sites for the resin cement allowing it to penetrate and fill the mesoporous structure, generating a hybrid layer of resin cement and zirconia at the interface. Therefore, the superior characteristics of the material guarantee that a mesoporous zirconia coating is an effective mechanical method to improve the bond strength with resin cement.

\subsection{Microstructure}

Compared with the smooth interface between the untreated interface in Figure 1(a), Figure 1(b) shows that the sandblasted ceramics resulted in a relatively irregular interface with the cements. Meanwhile, subcritical micro-cracks were clearly observed, which affected the bond strength between ceramics and resin cement. After conditioning with GI+HF, a three-dimensional network morphology was formed on the surface of the ceramics and the SEM image in Figure 1(c) revealed that this closely resembled the combination between zirconia and resin cement. This may be an ideal surface morphology for adhesive resin penetration. Meanwhile, SEM of mesoporous zirconia treatment in Figure 1(d) indicated that the resin cement penetrates into the substrate micro-retentions, inducing the interlocking formation at the ceramic-resin-cement interfaces. Small micro-cracks were observed and a harmonious bond interface between zirconia and resin cement was formed. The SEM images also reveal that GI+HF, as well as, mesoporous zirconia treatments may be beneficial for increasing the bond strength at the ceramic-resin cement interfaces, which was consistent with the microtensile bond strength test. 


\subsection{Resin cements}

The effect of luting agent on the adhesion to zirconia, in vitro, has previously been investigated. Although conventional cementation of zirconia restorations with luting agents (such as zinc phosphate cement) is able to provide adequate clinical fixation, adhesive cementation has the advantage of better retention and marginal adaptation [19]. Previous studies proposed that cements containing methacryloxy decyl phosphoric acid (MDP) monomers have the potential for bonding to zirconia [20]. This explains why Panavia F2.0 showed a higher bond strength to zirconia in the MDP-based luting system compared to the dimethacrylate-based resin luting system (RelyX Unicem). Higher bond strengths with Panavia F2.0 may indicate that the MDP monomer has the advantage of establishing a chemical bond with zirconia that results in chemical reactions involving the hydroxyl groups with the zirconia substrate at the interfacial level. However, previous studies indicated that there was no significant difference between Panavia F2.0 and RelyX Unicem [21], which is not consistent with the findings of this study.

\subsection{Microtensile bond strength test}

Tensile and shear tests are commonly performed to evaluate the retention of dental prostheses. However these tests can be sensitive to set-up alignment for non-uniform stress on the substrate due to a large bonding area [19] but more recent microtensile tests have overcome this limitation by using a smaller bonding area. In addition, MTBS tests require a smaller complex geometry for the sample, and achieve a more homogeneous stress distribution at the adhesive interface. Therefore, MTBS test are preferable [22].

The present study confirms that the mesoporous zirconia coating is an effective method to improve the bond strength between zirconia and resin cement. Various properties and indexes should satisfy a set of criteria before the method tested in clinical trials. Therefore, further investigation of the effect of the mesoporous modified surface on the mechanical properties of zirconia is required before clinical recommendations can be made.

\section{Conclusion}

Based on the work of this study, it can be concluded that Zirconia blocks modified with a mesoporous zirconia coating have higher microtensile bond strength when compared to airborne-particle abrasion treatment. In addition, the type of luting agent exhibits a significant effect on the MTBS of the zirconium oxide prior to artificial ageing.

\section{Acknowledgement}

This work was supported by Project on the Integration of Industry, Education and Research of Guangdong Province (2012B091000147), the Open Project Program of Shanghai Institute of Ceramics, Chinese Academy of Sciences (SKL201207SIC), Natural Science Foundation of Guangdong Province (9151051501000072), Foundation for High-level Talents in Higher Education of Guangdong, China (2011-68). 


\section{References}

[1] M.B. Blatz, A. Sadan and M. Kern, Resin-ceramic bonding: A review of the literature, J. Prosthet. Dent. 89 (2003), 268-74.

[2] S. Deville, J. Chevalier and L. Gremillard, Influence of surface finish and residual stresses on the ageing sensitivity of biomedical grade zirconia, Biomaterials 27 (2006), 2186-2192.

[3] F. Beuer, M. Stimmelmayr, W. Gernet, D. Edelhoff, J.F. Güh and M. Naumann, Prospective study of zirconia-based restorations: 3-year clinical results, Quintessence International 41 (2010), 631-637.

[4] M. Roediger, N. Gersdorff, A. Huels and S. Rinke, Prospective evaluation of zirconia posterior fixed partial dentures: Four-year clinical results, Int. J. Prosthodont. 23 (2010), 141-148.

[5] F. Beuer, D. Edelhoff, W. Gernet and J.A. Sorensen, Three-year clinical prospective evaluation of zirconia-based posterior fixed dental prostheses (FDPs), Clin. Oral. Investig. 13 (2009), 445-451.

[6] F.J. Burke, G.J. Fleming, D. Nathanson and P.M. Marquis, Are adhesive technologies needed to support ceramics? An assessment of the current evidence, J. Adhes. Dent. 4 (2000), 7-22.

[7] S.F. Rosenstiel, M.F. Land and B.J. Cripson, Dental luting agents: A review of the current literature, J. Prosthet. Dent. 80 (1998), 280-301.

[8] J.H. Phark, S. Duarte Jr, M. Blatz and A. Sadan, An in vitro evaluation of the long-term resin bond to a new densely sintered high-purity zirconium-oxide ceramic surface, Journal of Prosthetic Dentistry 101 (2009), 29-38.

[9] B.Yang, A. Barloi and M. Kern, Influence of airabrasion on zirconia ceramic bonding using an adhesive composite resin, Dent. Mater. 26 (2010), 44-50.

[10] A. Casucci, F. Monticelli, C. Goracci, C. Mazzitelli, A. Cantoroa and F. Papacchinia, Marco Ferrari Effect of surface pre-treatments on the zirconia ceramic-resin cement microtensile bond strength, Dental Materials 27 (2011), $1024-1030$.

[11] J. Teng, H. Wang, Y. Liao and X. Liang, Evaluation of a conditioning method to improve core-veneer bond strength of zirconia restorations, J. Prosthet. Dent. 107 (2012), 380-387.

[12] M. Özcan and P.K. Vallittu, Effect of surface conditioning methods on the bond strength of luting cements to ceramics, Dent. Mater.19 (2003), 825-831.

[13] J.P. Matinlinna, L.V. Lassila and P.K. Vallittu, Pilot evaluation of resin composite cement adhesion to zirconia using a novel silane system, Act. Odontol. Scand. 65 (2007), 44-51.

[14] B. Yang, A. Barloi and M. Kern, Influence of air abrasion on zirconia ceramic bonding using an adhesive composite resin, Dent. Mater. 26 (2010), 44-50.

[15] M.B. Blatz, A, Sadan, J, Martin and B. Lang, In vitro evaluation of shear bond strengths of resin to densely sintered high-purity zirconium-oxide ceramic after long-term storage and thermal cycling, J. Prosthet. Dent. 91 (2004), 356-362.

[16] M. Wolfart, F. Lehmann, S. Wolfart and M. Kern, Durability of the resin bond strength to zirconia ceramic after using different surface conditioning methods, Dent. Mater. 23 (2007), 45-50.

[17] Y. Zhang, B.R. Lawn, E.D. Rekow and V.P. Thompson, Effect of sandblasting on the long-term performance of dental ceramics, J. Biomed. Mater. Res. B Appl. Biomater. 71 (2004), 381-386.

[18] A. Casucci, F. Monticelli, C. Goracci, C. Mazzitelli, A. Cantoro, F. Papacchini and M. Ferrari, Effect of surface pre-treatments on the zirconia ceramic-resin cement microtensile bond strength, Dental Materials 27 (2011), 1024-1030.

[19] S.S. Atsu, M.A. Kilicarslan, H.C. Kucukesmen and P.S. Aka, Effect of zirconium-oxide ceramic surface treatments on the bond strength to adhesive resin, J. Proshtet. Dent. 95 (2006), 430-436.

[20] R.C. Oyagüe, F. Monticelli, M. Toledano, E. Osorio, M. Ferrari and R. Osorio, Influence of surface treatments and resin cement selection on bonding to densely sintered zirconium-oxide ceramic, Dental Materials 25 (2009), 172-179.

[21] C. Goracci, S. Grandini, M. Bossu, E. Bertelli and M.Ferrari, Laboratory assessment of the retentive potential of adhesive posts: A review, J. Dent. 35 (2007), 827-835.

[22] H.L. de Castro, P.H. Corazza, T. de. A. Paes-Júnior and A. Della Bona, Influence of Y-TZP ceramic treatment and different resin cements on bond strength to dentin, Dental Materials 28 (2012), 1191-1197 